South Africa, like most Southern African Development Community (SADC) member states with precarious working conditions, still has limited and/or absent access to OEHS. This is a phenomenon that 'echoes an uncaring society', especially on the part of the South African tripartite leaders (regulator, employer and trade union movement), which suggest that as a country we may be falling short of the African spirit of UBUNTU.

Broadly UBUNTU is an essential human virtue with compassion and humanity embedded in it. It embodies the spirit of the greater good of growing together and caring for one another as human beings, families, communities and nations. In OEHS numerous statutes give responsibilities to tripartite leaders on compliance with minimum OEHS standards and services for the workforce. Thus, this paper looks at the spirit of UBUNTU and OEHS by addressing the question: 'Do tripartite leaders (human beings) in their roles in managing the country's economy and providing OEHS services - which are a basic human right for the workforce (human beings) - consider the spirit of UBUNTU in executing their responsibilities?'

\section{C QUALITY OF WORKING LIFE AND VALUE OF WORK OF CANCER SURVIVORS}

Angela GEM de Boer*, Merel de Jong, Sietske J Tamminga, Monique HW Frings-Dresen. Academic Medical Centre, Department Coronel Institute of Occupational Health. Amsterdam Public Health research institute, Amsterdam, the Netherlands

\subsection{6/oemed-2018-ICOHabstracts.614}

Introduction Previous research on employees with a chronic disease, including employees who have been diagnosed and treated for cancer, mainly focused on work outcomes such as absence from work, productivity and unemployment. It has been seldom taken into account how employees with a chronic disease experience their working life and how they value their work.

The concept of Quality of Working Life encompasses the subjective work experiences of working individuals. This study aimed to:

- describe issues that contribute to the Quality of Working Life (QWL) of employees with a chronic physical disease, and

- to identify important QWL issues of cancer survivors.

Methods A systematic literature search was conducted to identify experiences and perceptions during the working life of employees with a chronic physical disease. These experiences were synthesised into issues that contributed to their QWL. During three focus groups with 24 cancer survivors, issues contributing to their QWL were discussed.

Results An overview of 73 QWL issues was found which could be identified into five categories:

- individual work perceptions including issues about enjoyment and evaluation work of life priorities;

- social structure and environment containing issues about disclosure, discrimination, misunderstanding and awareness by employers and colleagues;

- organisational characteristics such as communication and decision making;

- job characteristics including work accommodations; and

- effect of disease and treatment on work ability.
The issues discussed by cancer survivors in the focus groups included several themes including feelings, such as 'feeling safe and familiar at work' and work issues such as 'working gives me structure in life'.

Discussion This study described QWL issues of employees with a chronic physical disease and of cancer survivors. These issues may function as a starting point for occupational support and evaluation of OHS studies.

\section{5d MUNDANE JOBS - MOTIVATION FOR WORK}

Ashish Mittal. CEO, Occupational Health and Safety Management Consultancy Services, New Delhi, India

\subsection{6/oemed-2018-ICOHabstracts.615}

Introduction Mundane (Latin mundānus=worldly) jobs are unexciting, boring, monotonous day to day work jeopardising psychosocial health and safety of the workers at the workplace. These routine jobs do require workers to perform with sufficient levels of task identity, task significance, and skill variety to feel their work has meaning and value. Sufficiently high levels of autonomy and Task Feedback inspires the worker to feel responsibility for the work. The combined effect of these psychological states results in desired personal and work outcomes: intrinsic motivation, job satisfaction, performance quality, low absenteeism, and low turnover rate.

Methods Workers involved in many of the hazardous, mundane works (sewage cleaning and maintenance workers, tannery workers, e-waste workers, brick kiln workers, stone crusher workers, landfill site workers, welders, street vendors etc.) with poor health outcomes related to their workplace exposures having high morbidity and mortality were interviewed/reviewed during the base line of their respective occupational health studies. Reasons for them choosing the said occupation, willingness to continuing the same work, or choosing the same work for their kids were looked for.

Results The collective response of sewage workers is - the work is regarded as menial with no dignity of labour, discriminatory, stigmatising, low paid, with no job security, no secure livelihood or other work options, no promotions, having no personal identification being known as worker only and characteristically lack of fundamental rights of equality, life and liberty. They have no bargaining power for wages, safety and health, to demand, to resist, to protest, with no allowances/benefits, and they hide community, caste and their identity from society at large.

Discussion Although people do continue with their mundane jobs with some intrinsic basic motivations, but we need to integrate the psychosocial aspects and behavioural modifications of work addressing the above issues to promote health and safety at workplace.

\section{5e HEALTH PROMOTION AND CONSTRUCTIVE ERGONOMICS: AN INTEGRATED DEVELOPMENTAL PERSPECTIVE TO IMPROVE SUSTAINABLE WORKING CONDITIONS AND WELL-BEING AT WORK}

Y Roquelaure. INSERM, IRSET, ESTER Team, University of Angers, Angers, France

10.1136/oemed-2018-ICOHabstracts.616 